\title{
PEMAKAIAN DEIKSIS PERSONA DALAM CERPEN DI HARIAN REPUBLIKA
}

\author{
Misbah Priagung Nursalim ${ }^{1}$, Syahrobi Nur Alam² \\ Fakultas Sastra, Universitas Pamulang \\ ${ }^{1}$ dosen00942@unpam.ac.id, ${ }^{2}$ syahrobinuralam@gmail.com
}

\begin{abstract}
Abstrak
Deiksis yang referennya tidak tetap sering digunakan dalam teks sastra, salah satunya cerpen. Penelitian ini secara khusus mengkaji pemakaian deiksis persona dalam cerpen di harian Republika. Adapun tujuan dari penelitian ini, yaitu mengkaji bentuk, fungsi, dan makna deiksis persona dalam cerpen di surat kabar Republika. Penelitian ini menggunakan metode deskriptif kualitatif dan untuk pengumpulan data menggunakan metode dokumentasi. Data penelitian berupa cerpen pada koran Republika edisi Januari 2017. Setelah melakukan penelitian, penulis menemukan beberapa bentuk deiksis persona dalam cerpen tersebut seperti pronomina persona pertama tunggal dan jamak, pronomina persona kedua tunggal dan jamak, dan pronomina persona ketiga tunggal dan jamak. Kemudian, menemukan fungsi deiksis persona dalam cerpen tersebut seperti merujuk pada orang yang berbicara, merujuk pada orang yang diajak bicara, dan merujuk pada orang yang dibicarakan dalam cerita.
\end{abstract}

Kata Kunci: Pragmatik, deiksis, deiksis persona, cerpen Republika

\begin{abstract}
Deixis, whose referents are not always used in literary texts, one of which is a short story. This study specifically examines the use of person deixis in short stories in the Republika daily. The purpose of this study is to examine the form, function, and meaning of person deixis in the short story in the Republika newspaper. This study uses a qualitative descriptive method and for data collection using the documentation method. Research data in the form of short stories in the January 2017 issue of Republika newspaper. After conducting research, the author found several forms of person deixis in the short story such as singular plural singular pronouns, second singular plural pronouns, and singular and plural third person pronouns. Then find the person deixis function in the short story as referring to the person who speaks, refers to the person being spoken to, and refers to the person being talked about in the story.
\end{abstract}

Keywords: Pragmatic, deixis, deixis persona, Republika short story

\section{PENDAHULUAN}

Bahasa merupakan alat komunikasi dan alat interaksi yang hanya dimiliki manusia. Dengan bahasa, sebagai manusia mampu menyampaikan pesan, gagasan, atau perasaan kepada lawan biacara atau mitra tutur, baik dalam keadaan formal atau dengan bahasa sehari-hari.
Pada saat berkomunikasi dan berinteraksi, seseorang harus memahami situasi atau konteks agar tidak terjadi kesalahpahaman antara penutur dan mitra tutur. Dalam ilmu kebahasaan atau linguistik terdapat cabang ilmu yang dikenal dengan istilah pragmatik. Pragmatik merupakan studi tentang maksud atau makna yang disampaikan penutur dan ditafsirkan oleh mitra tutur 
yang juga mempertimbangkan konteks dari suatu pembicaraan. Dengan memperhatikan konteks, komunikasi akan berjalan lebih baik. Chaer dan Agustina, 2010:56 menjelaskan bahwa pragmatik lazim diberi definisi sebagai telaah mengenai hubungan di antara lambang dengan penafsiran.

Bentuk interaksi dan komunikasi dapat berbentuk tuturan langsung dan tidak langsung. Keduanya dapat dikaji dengan ilmu pragmatik. Dalam tuturan langsung seperti berbicara satu dengan yang lainya, maksud pembicaraan dapat ditanyakan langsung oleh kedua pembicara tersebut. Namun, di dalam tuturan tidak langsung seperti tulisan baik surat atau cerita dan lain-lain harus sangat memperhatikan tulisan tersebut baik maksud dan apalagi rujukan dalam tulisan tersebut. Rujukan atau kata ganti yang berubah ubah disebut deiksis.

Deiksis merupakan bagian dari ilmu pragmatik berkaitan dengan pengungkapan sesuatu yang menjadi acuan atau referen yang berubah-ubah dalam komunikasi dengan menggunakan sarana bahasa. Deiksis baru dapat diketahui maknanya jika telah dikahui siapa, di mana, dan kapan kata itu diucapkan, yaitu terikat dengan konteks yang diacu oleh penutur.

Deiksis digunakan dalam komunikasi lisan maupun tulisan. Dalam komunikasi lisan digunakan dalam berbicara formal, santai, dan sebagainya. Lain halnya komunikasi tulisan, deiksis digunakan dalam surat, buku, dan media sastra, seperti novel, cerpen, dan puisi.

Cerpen yang merupakan bagian dari sastra, saat ini telah banyak di publikasikan lewat banyak media. Salah satu media yang konsisten menghadirkan cerpen adalah media cetak koran. Di antara koran tersebut adalah Kompas, Republika, Jawa Pos, Suara Merdeka, Tempo, dan Media Indonesia. Cerpen yang diterbitkan koran tersebut sering disebut cerpen koran minggu, karena hanya terbit pada hari minggu di setiap korannya. Cerpen koran tersebut merupakan apresiasi seni media cetak Indonesia terhadap karya sastra Indonesia, khususnya cerpen. Berikut ini adalah contoh data pemakaian deiksis persona pada cerpen Republika:

\section{Data 001}

"Aku tak mau tau. Semua tembok yang kau buat tak ada gunanya. Tembok itu tidak bisa menyembunyikanku. Tembok itu tampak transparan dan terlihat dari dalam atau luar."

Data 002

"Ampuni saya! Saya tidak dapat membangun pagar sesuai kehendak."

Data 003

Keh Pusri memunguti kelereng yang berserakan tanpa tersisa. Sementara, dari jauh anak-anak yang lari tadi mengintip dari rerimbunan pepohonan sambil menahan debar. "Habislah kita, ujar mereka.

Data 004

"Kamu harus meraba bekas sabetan itu agar merasakan kesalahan yang kamu lakukan," kata Ibu. Aku tidak bisa tidur karena ngilu dan perih semalaman.

Pada data (001) dalam penggalan Cerpen berjudul "Dinding Kalbu" edisi 8 Januari 2017 diatas terdapat pemakaian deiksis pronomina persona pertama tunggal "Aku" dan bentuk -ku. Bentuk tersebut merujuk kepada Paryo seorang pensiunan jendral. Rujukan tersebut dapat diketahui setelah membaca teks secara lengkap. Fungsi pemakaian 
deiksis persona pertama tunggal dalam bentuk "Aku" dan "-ku" tersebut mengarah pada orang yang berbicara yaitu Paryo. Kemudian, untuk menunjukkan keakraban antara pembicara dan pendengar. Dalam data (001) pembicara atau penutur tersebut sama atau lebih tinggi status sosialnya dengan pendengar atau mitra tutur.

Pada data (002) dalam penggalan cerpen berjudul "Dinding Kalbu" edisi 8 Januari 2017 di atas terdapat pemakaian deiksis pronomina persona pertama tunggal "Saya." Bentuk tersebut merujuk kepada Tarno yang merupakan tokoh utama dalam cerpen tersebut. Rujukan tersebut dapat diketahui setelah membaca teks dengan seksama. Fungsi pemakaian deiksis persona pertama tunggal dalam bentuk "Saya" tersebut juga untuk mengarah pada orang yang berbicara yaitu Tarno. Berbeda dengan data (001), pada data (002) bentuk deiksis persona pertama "Saya" menunjukkan kesan resmi atau meberikan rasa hormat penutur kepada mitra tutur. Penutur lebih rendah status sosialnya dari lawan tutur sehingga kata "Saya" memberikan kesan hormat.

Pada data (003) dalam penggalan cerpen berjudul "Rotan Keh Pusri" edisi 15 Januari 2017 di atas terdapat pemakian deiksis pronomina persona pertama jamak "Kita". Pronomina "Kita" tersebut merujuk pada anak-anak yang lari. Rujukan tersebut diketahui setelah membaca teks secara utuh. Fungsi pemakaian deiksis persona pronomina "Kita" mengarah pada orang yang berbicara dan orang yang bersamanya.

Pada data (004) dalam penggalan cerpen berjudul "Rotan Keh Pusri" edisi 15 Januari 2017 di atas terdapat pemakaian deiksis pronomina persona kedua tunggal "Kamu." Pronomina persona "Kamu" dalam penggalan cerpen tersebut merujuk kepada tokoh utama yang bercerita. Rujukan tersebut kita ketahui setelah kita membaca dan memahami kalimat tersebut secara utuh. Fungsi pemakaian deiksis pronomina persona kedua tunggal "Kamu" mengarah pada orang yang di ajak bicara. Pronomina "kamu" digunakan untuk memberikan kesan akrab yaitu antara orang tua terhadap orang muda (anaknya) yang telah dikenal dengan baik dan lama.

Beberapa kata ganti tersebut digunakan untuk menyebutkan nama atau orang yang diajak bicara, tempat, atau waktu dalam kondisi atau situasi yang tertentu yang disebut pemakaian deiksis. Adapun deiksis terbagi menjadi lima macam, yaitu deiksis orang atau pesona, deiksis tempat, deiksis waktu, deiksis wacana dan deiksis sosial. Dari kelima macam deiksis tersebut, deiksis personalah yang paling banyak dipakai karena berkaitan dengan orang yang diajak biacara ataupun yang dimaksudkan dalam pembicaran. Seperti kata aku, kita, kami, engkau, dia dan lain sebaginya yang referenya dapat berubahubah.

\section{METODE PENELITIAN}

Penelitian ini merupakan jenis penelitian kualitatif dengan desian deskriptif. Menurut Krik \& Miller (dalam Djajasudarma, 2010: 11) penelitian kualitatif adalah tradisi tertentu dalam ilmu pengetahuan sosial yang secara fundamental bergantung pada pengamatan mausia dalam kawasanya sendiri dan hubungan dengan masyarakat tersebut melaui bahasanya, serta peristilahan. Motode penelitian deskriptif adalah metode yang bertujuan membuat deskripsi; maksudnya membuat gambaran, lukisan secara sistematis, faktual dan akurat mengenai data, sifat-sifat serta hubungan fenomena-fenomena yang diteliti. Sumber data berupa kumpulan cerpen 
yang dimuat dalam koran Republika edisi Januari 2017 yang dikumpulkan menggunakan metode dokumentasi. Objek yang dikaji adalah pemakaian deiksis persona dalam kumpulan cerpen Republika. Sesuai data cerpen Republika edisi Januari 2017 yang menjadi objek kajian, yaitu:

1. Cerpen berjudul "Dinding Kalbu" edisi 8 januari 2017 oleh Risda Nur Widia.

2. Cerpen berjudul "Rotan Keh Pusri" edisi 15 Januari 2017 oleh Sule Subaweh atau Sulaiman.

3. Cerpen berjudul "Paris, Salju dan Gerimis" edisi 22 Januari 2017 oleh Irwan Kelana.

4. Cerpen berjudul "Derai dan Luruh" edisi 29 Januari 2017 oleh D Nilasyah atau Desni Intan Suri.

\section{HASIL DAN PEMBAHASAN}

1. Bentuk Deiksis

a. Bentuk Deiksis dalam Cerpen Dinding Kalbu

Di dalam cerpen Dinding Kalbu terdapat bentuk pronomina persona pertama tunggal saya, $a k u$, dan $-k u$. Tidak terdapat bentuk pronomina persona pertama tunggal daku dan $k u-$.

Terdapat bentuk pronomina persona pertama jamak kita. Namun, dalam cerpen ini tidak terdapat bentuk pronomina persona pertama jamak kami. Terdapat bentuk pronomina persona kedua tunggal kau- dan $m u$. Tidak terdapat bentuk pronomina persona kedua tunggal engkau, kamu, anda, dan dikau. Terdapat bentuk pronomina persona ketiga tunggal ia dan -nya. Tidak terdapat bentuk pronomina persona ketiga tunggal dia dan beliau. Terdapat bentuk pronomina persona ketiga jamak yaitu mereka.

Di dalam cerpen tersebut terdapat pemakaian deiksis persona sebanyak 78 pronomina, yaitu prononomina persona pertama tunggal sebanyak 14 pronomina, pronomina persona pertama jamak sebanyak 1 pronomina, pronomina persona kedua tunggal sebanyak 13 pronomina, pronomina persona ketiga tunggal sebanyak 48 pronomina, dan pronomina persona ketiga jamak sebayak 2 pronomina. Namun, dalam cerpen ini tidak terdapat pronomina kedua jamak.

Pronomina persona yang paling banyak muncul dalam cerpen ini adalah pronomina persona ketiga tunggal sebanyak 48 pronomina. Hal tesebut dikarenakan jalan cerita dalam cerpen, pengarang mempunyai sudut pandang orang ketiga serba tahu.

b. Bentuk Deiksis dalam Cerpen Rotan Keh Pusri

Di dalam cerpen Rotan Keh Pusri terdapat bentuk pronomina persona pertama tunggal $a k u$, dan $-k u$. Namun, dalam cerpen ini tidak terdapat bentuk pronomina persona pertama tunggal saya, daku dan $k u-$. Terdapat bentuk pronomina persona pertama jamak kami dan kita. Terdapat bentuk pronomina persona kedua tunggal kamu dan - mu. Tidak terdapat bentuk pronomina persona kedua tunggal engkau, anda, dikau, dan kau-. Terdapat bentuk pronomina persona kedua jamak kalian. Terdapat bentuk pronomina persona ketiga tunggal dia dan nya. Tidak terdapat bentuk 
pronomina persona ketiga tunggal ia dan beliau. Terdapat bentuk pronomina persona ketiga jamak yaitu mereka.

Di dalam cerpen tersebut terdapat pemakaian deiksis persona sebanyak 92 pronomina yaitu prononomina persona pertama tunggal sebanyak 28 pronomina, pronomina persona pertama jamak sebanyak 40 pronomina, pronomina persona kedua tunggal sebanyak 5pronomina, pronominal persona kedua jamak sebanyak 1 pronomina, pronomina persona ketiga tunggal sebanyak 17 pronomina, dan pronomina persona ketiga jamak sebayak 1 pronomina. Pronomina persona yang paling banyak muncul dalam cerpen ini adalah pronomina persona pertama jamak sebanyak 40 pronomina dan pronomina persona pertama tunggal sebanyak 28 pronomina. Hal tesebut dikarenakan jalan cerita dalam cerpen, pengarang mempunyai sudut pandang orang pertama pelaku utama.

c. Bentuk Deiksis Persona dalam Cerpen Paris, Salju dan Gerimis Di dalam cerpen Paris, Salju dan Gerimis terdapat bentuk pronomina persona pertama tunggal saya, aku, $k u$ - dan $-k u$. Namun, dalam cerpen ini tidak terdapat bentuk pronomina persona pertama tunggal daku. Terdapat bentuk pronomina persona pertama jamak kita dan kami. Terdapat bentuk pronomina persona kedua tunggal engkau, kamu, kau-dan $-m u$. Tidak terdapat bentuk pronomina persona kedua tunggal anda dan dikau. Terdapat bentuk pronomina persona ketiga tunggal ia, dia, nya dan beliau. Di dalam cerpen tersebut terdapat bentuk pronomina persona ketiga jamak yaitu mereka.

Di dalam cerpen terdapat pemakaian deiksis persona sebanyak 213 pronomina, yaitu prononomina persona pertama tunggal sebanyak 105 pronomina, pronomina persona pertama jamak sebanyak 36 pronomina, pronomina persona kedua tunggal sebanyak 22, pronomina persona ketiga tunggal sebanyak 42 pronomina, dan pronomina persona ketiga jamak sebayak 8 pronomina. Namun, dalam cerpen ini tidak terdapat pronomina kedua jamak. Pronomina persona yang paling banyak muncul dalam cerpen ini adalah pronomina persona pertama sebanyak 141 pronomina. Terdiri dari pronomina persona pertama tunggal sebanyak 105 pronomina dan pronomina persona pertama jamak sebanyak 36 pronomina. Hal tesebut dikarenakan jalan cerita dalam cerpen, pengarang mempunyai sudut pandang orang pertama pelaku utama.

d. Bentuk Deiksis Persona dalam Cerpen Derai dan Luruh

Di dalam cerpen tersebut terdapat bentuk pronomina persona pertama tunggal $a k u,-k u$ dan $k u$-. Tidak terdapat bentuk pronomina persona pertama tunggal saya dan daku. Terdapat bentuk pronomina persona pertama jamak kita. Tidak terdapat bentuk pronomina persona pertama jamak kami. Terdapat bentuk pronomina persona kedua tunggal, kamu, kau- dan $-m u$. Tidak terdapat 
bentuk pronomina persona kedua tunggal engkau, anda dan dikau. Tidak terdapat bentuk pronomina persona kedua jamak. Terdapat bentuk pronomina persona ketiga tunggal ia, dan -nya. Namun, dalam cerpen tersebut tidak terdapat bentuk pronomina persona ketiga tunggal dia dan beliau.

Di dalam cerpen tersebut terdapat pemakaian deiksis persona sebanyak 80 pronomina, yaitu prononomina persona pertama tunggal sebanyak 10 pronomina, pronomina persona pertama jamak sebanyak 7 pronomina, pronomina persona kedua tunggal sebanyak 18 pronomina, pronomina persona ketiga tunggal sebanyak 28 pronomina, dan pronomina persona ketiga jamak sebayak 17 pronomina. Namun, dalam cerpen ini tidak terdapat pronomina kedua jamak. Pronomina persona yang paling banyak muncul dalam cerpen ini adalah pronomina persona ketiga sebanyak 45 pronomina. Terdiri dari pronomina persona ketiga tunggal sebanyak 28 pronomina dan pronomina persona ketiga jamak sebanyak 17 pronomina. Hal tesebut dikarenakan jalan cerita dalam cerpen tersebut pengarang mempunyai sudut pandang orang ketiga serba tahu.

\section{Fungsi Pemakaian Deiksis Persona dalam Kumpulan Cerpen Republika}

a. Merujuk Pada Orang yang Berbicara

Deiksis persona yang rujukannya berubah-ubah digunakan penulis cerpen untuk mengarah atau merujuk pada orang yang berbicara di dalam cerita agar tidak terjadi pengulangan nomina. Seperti yang sudah dijelaskan sebelumnya, deiksis persona terbagi menjadi pronomina persona pertama, kedua, dan ketiga. Berikut adalah data pronomina persona pertama yang merujuk pada orang yang berbicara:

Data 001

"Jika dalam waktu tiga bulan ke depan tembok yang kau bangun belum selesai," sambil moncong senapan menuding ke Tarno. "Jangan salahkan $a k u$ jika istri dan anakmu kehilangan kebahagiannya!"

"Jangan...," tarno memohon.

"Sudah miliyaran $a k u$ habiskan uang untuk membangun tembok itu!"

Data 001 tersebut merupakan cerpen berjudul Dinding kalbu edisi 8 Januari 2017. Pada data tersebut terdapat pronomina persona pertama tunggal aku. Kata tersebut merujuk pada nomina Paryo yang merupakan salah satu tokoh dalam cerpen tersebut. Di dalam cerita, Paryo berbicara kepada Tarno yang merupakan tokoh utama cerpen tersebut. Maka pengarang cerpen menggunakan pronomina persona $a k u$ sebagai pengganti nomina Paryo yang berbicara. Pemakaian pronomina $a k u$ karena di dalam cerita, Paryo lebih tinggi status sosialnya dari Tarno yang menjadi lawan tuturnya, maka fungsi deiksis persona pronomina $a k u$ pada cerpen 
tersebut merujuk pada orang yang berbicara. Selain itu, terdapat data lain sebagai berikut:

"Ampuni saya! Saya tidak dapat membangun pagar sesuai kehendak."

"Sudahlah lupakan," suara sang jendral bersahabat.

Tarno tercenung. "Maksudnya?"

"Sudah lupakan. Sampai kapan pun kau tidak bisa membuat pagar itu. Pagar itu berbeda dari pagar pada umumnya," ramah sang jendral berujar.

Pada data diatas yang juga merupakan cerpen berjudul Dinding kalbu edisi 8 Januari 2017. Pada data tersebut terdapat pronomina persona pertama tunggal saya. Kata tersebut merujuk pada nomina Tarno yang merupakan tokoh utama dalam cerpen tersebut. Di dalam cerita, Tarno berbicara kepada Paryo yang merupakan salah satu tokoh dalam cerpen tersebut. Maka pengarang cerpen menggunakan pronomina persona saya sebagai pengganti nomina Tarno yang berbicara. Artinya, fungsi deiksis persona pronomina $a k u$ pada cerpen tersebut merujuk pada orang yang berbicara.

Pemakaian pronomina saya dalam cerpen tersebut karena di dalam cerita, Tarno lebih rendah status sosialnya dari Paryo yang menjadi lawan tuturnya. Tarno merupakan seorang arsitektur yang ditugaskan Paryo membangun sebuah tembok. Paryo sendiri adalah seorang pensiunan jendral yang kini menduduki kursi mentri. Perbedaan pemakaian pronomina aku dan saya bergantung konteks. Dalam hal ini konteks social, yaitu status sosial yang lebih tinggi dengan yang lebih rendah.

b. Merujuk pada Orang Yang Diajak Bicara

Deiksis persona juga berfungsi untuk merujuk pada orang yang diajak bicara, seperti pada data di bawah ini:
Data 002
"Rasa sakit itu akan cepat hilang, tapi kepercayaan tidak akan hilang secepat rasa perih $m u$, Cong," kata ibu setelah aku mengadu karena dihukum oleh Keh Pusri untuk kedua kalinya.
"Tapi kan bukan aku yang bersalah, Bu."
"Kamu sudah di cap merah oleh Keh Pusri. Кати akan terus menjadi tersangka dalam beberapa persoalan, Cong sebelum..."

Data 002 tersebut merupakan cerpen Republika tanggal 12 Januari 2017 dengan judul Rotan Keh Pusri. Pada data tersebut terdapat bentuk pronomina persona kedua tunggal kamu, dan -mu. Pronomina persona tersebut merujuk pada orang yang di ajak bicara, yaitu tokoh aku yang merupakan tokoh utama dalam cerpen. Pada tuturan tersebut tokoh aku di ajak bicara oleh Ibunya. Artinya fungsi deiksis persona pronomina kamu dan - 
mu pada cerpen merujuk pada orang yang diajak bicara.

Data 004

"Aku tidak menduga kau bisa masuk ke dunia model rai..."

"setiap orang tidak sama waktunya bisa menerima kodrat dirinya."

"kalau dulu kau sepermpuan saat ini, aku pasti akan suka dijodohkan almarhum Uwo Rabin,"

"almarhum uwo Rabin tahu, aku takkan pernah mau."

Data 004 merupakan cerpen Republika tanggal 29 Januari 2017 dengan judul Derai dan Luruh. Pada data tersebut terdapat bentuk pronomina persona kedua tunggal kau. Pronomina persona merujuk pada Derai yang merupakan tokoh utama dalam cerpen. Pada tuturan tersebut Derai di ajak bicara oleh Luruh yang juga sebagai tokoh utama dalam cerita. Artinya, fungsi deiksis persona pronomina kau pada cerpen merajuk pada orang yang diajak bicara.

c. Merujuk pada Orang yang Dibicarakan

Deiksis persona juga berfungsi untuk mengarah pada orang yang dibicarakan. Seperti pada data di bawah ini:

\section{Data 003}

"Sekarang apa rencanamu, Irfan?" gantian, Khairin yang "Menembak" aku. Dia tersenyum kecil memperlihatkan barisan giginya yang putih teratur. Ah, kalau mau, Khairin bisa jadi model pasta gigi.

"Rencanaku? Aku sekarang akan menemui ayahmu, minta izin melamarmu. Pekan depan, besok, atau kalau beliau setuju, hari ini juga."

Lagi-lagi Khairin tersenyum manis.

Data 003 merupakan cerpen Republika tanggal 22 Januari 2017 dengan judul Paris Salju dan Gerimis. Pada data tersebut terdapat bentuk pronomina persona ketiga tunggal dia, -nya dan beliau. Pronomina persona dia dan -nya merujuk pada Khairin, yaitu seseorang diiceritakan atau dibicarakan oleh Irfan yang sebagai tokoh utama yang bercerita, sedangkan pronomina persona Beliau merujuk kepada Ayahnya Khairin, yaitu seseorang yang Irfan bicarakan kepada Khairin. Artinya fungsi, deiksis persona pronomina dia, nya dan beliau pada cerpen merujuk pada orang yang dibicarakan.

\section{SIMPULAN}

Setelah penulis melakukan pengamatan dalam periode Januari 2017 pada cerpen yang termuat di harian Republika, penulis menemukan bentuk, fungsi, dan makna pemakaian deiksis persona dalam cerpen tersebut. Berdasarkan penelitian yang telah dilakukan, penulis menyimpulkan bahwa terdapat bentuk pemakaian deiksis persona sebagai berikut: 
Di dalam cerpen terdapat 1014 pronomina persona. Pronomina terdiri dari bentuk pronomina persona pertama tunggal sebanyak 423 pronomina atau setara dengan 41,71\%, bentuk pronomina persona pertama jamak sebanyak 130 pronomina atau setara dengan $12,82 \%$, bentuk pronomina persona kedua tunggal sebanyak 129 pronomina atau setara dengan $12,72 \%$, bentuk pronomina persona kedua jamak sebanyak 4 pronomina atau setara $0,39 \%$, bentuk pronomina persona ketiga tunggal sebanyak 282 pronomina atau setara dengan $27,81 \%$, dan bentuk pronomina persona ketiga jamak sebanyak 46 pronomina atau setara dengan $4,53 \%$.

Bentuk pronomina yang paling banyak muncul adalah pronomina persona pertama tunggal sebanyak 423 pronomina atau setara dengan $47,71 \%$, kemudian disusul oleh pronomina persona ketiga tunggal sebanyak 282 pronomina atau setara dengan $27,81 \%$. Kemunculan dominan dari pronomina persona pertama tunggal dan pronomina persona ketiga tunggal di dalam cerpen erat kaitannya dengan sudut pandang pengarang. Sudut pandang pengarang sangat memengaruhi pemakaian deiksis persona dalam cerpen.

Selanjtnya penulis menganalisis fungsi pemakian deiksis persona dalam cerpen di harian Republika, yaitu:

1. Merujuk pada orang yang berbicara Fungsi deiksis persona yang merujuk kepada orang berbicara adalah pronomina persona pertama baik bentuk tunggal seperti saya, aku, -ku, dan $k u$-, dan bentuk jamak seperti kami dan kita. Pengarang cerpen menggunakan pronomina persona pertama untuk merujuk kepada orang yang berbicara dalam cerita serta agar tidak terjadi penyebutan nomina yang berulang-ulang dalam cerita tersebut.
2. Merujuk pada orang yang diajak bicara

Fungsi deiksis persona yang merujuk pada orang yang diajak bicara adalah pronomina persona kedua baik bentuk tunggal seperti engkau, kamu, $k a u$, dan $-m u$, dan bentuk jamak yaitu kalian. Pengarang cerpen menggunakan pronomina persona kedua untuk merujuk kepada orang yang diajak bicara di dalam cerita.

3. Merujuk pada orang yang dibicarakan

Fungsi deiksis persona yang merujuk pada orang yang dibicarakan adalah pronomina persona ketiga baik bentuk tunggal seperti ia, dia, -nya dan beliau, dan bentuk jamak, yaitu mereka. Pengarang cerpen menggunakan pronomina persona ketiga untuk merujuk kepada orang yang dibicarakan di dalam cerita.

\section{DAFTAR PUSTAKA}

Chaer, A. dan Agustina, L. (2010). Sosiolinguistik: Perkenalan Awal. Jakarta : Rineka Cipta.

Djajasudarma, F. (2010). Metode Linguistik, Ancangan Metode Penelitian dan Kajian. Bandung: PT Refika Aditama.

Kelana, I. "Paris, salju, dan Gerimis." Republika, edisi 019/Th. ke25/22 Januari 2017

Sulaiman. "Rotan Keh Pusri." Republika, edisi 012/Tahun ke25/15 Januari 2017

Suri, D. I. "Derai dan Luruh." Republika, edisi 025/Tahun ke-25/29 Januari 2017

Widia, R. N. "Dinding Kalbu." Republika, edisi 005/Tahun ke25/8 Januari 201 